Revista aSEPHallus de Orientação Lacaniana Núcleo Sephora de Pesquisa sobre o Moderno e o Contemporâneo ISSN $1809-709 \mathrm{X}$

\title{
Me chame pelo meu nome
}

\author{
Alexandre Costa Val \\ Pós-doutor em Estudos Psicanalíticos pela Universidade Federal de Minas Gerais (Minas Gerais, Brasil) \\ Professor Adjunto da Escola de Medicina da Universidade Federal de Ouro Preto (Minas Gerais, Brasil) \\ Membro do Núcleo de Investigação das Subjetividades Contemporâneas (NISC), Escola de Medicina da \\ Universidade Federal de Ouro Preto (Minas Gerais, Brasil) \\ E-mail: alecostaval@yahoo.com.br
}

Resumo: Este ensaio propõe uma reflexão sobre o lugar do psicanalista diante das transformações jurídicas, políticas, subjetivas e sociais que fazem parte do contemporâneo, tendo como foco a questão do nome social das pessoas trans. Para isso, as regulamentações brasileiras são examinadas e tensionadas com a Ley de Identidad de Género da Argentina a partir do relato das experiências de três sujeitos. Discute-se, finalmente, a possibilidade de que certas leis acomodem melhor os sujeitos e suas singularidades, diminuindo assim a segregação social.

Palavras-chaves: psicanálise; sexualidade; nome social; política.

Appele-moi par mon nom: Cet essai propose une réflexion sur la place du psychanalyste face aux transformations juridiques, politiques, subjectives et sociales qui font partie du contemporain, en se centrant sur la question du nom social des personnes trans. Pour cela, les réglementations brésiliennes sont examinées et tendues avec la Loi de l'Identité du Genre de l'Argentine à partir du rapport de l'expérience de trois sujets. Finalement, il sera discuté de la possibilité que certaines lois satisfassent mieux les sujets et leur singularité, en diminuant ainsi la ségrégation sociale.

Mots-Clés: Sexualité; nom social; psychanalyse; politique.

Call me by my name: This essay aims to propose a reflection on the psychoanalyst's place toward the juridical, political, subjective and social transformations that are part of the contemporary moment, focusing on the subject of trans people's social name. In order to do so, the Brazilian regulations are examined in comparison with the Law of Gender Identity in Argentina based on the report of the experiences of three subjects. Finally, it is discussed the possibility that certain laws will better accommodate the subjects and their singularities, thus reducing social segregation.

Keywords: psychoanalysis; sexuality; social name; politics. 


\title{
Me chame pelo meu nome
}

\section{Alexandre Costa Val}

\author{
Já fui loura, já fui morena, \\ já fui Margarida e Beatriz. \\ Já fui Maria e Madalena. \\ Só não pude ser como quis. \\ (Meireles, C. Mulher ao Espelho) ${ }^{1}$.
}

\section{Introdução}

A diversidade das experiências contemporâneas relacionadas aos gêneros e às sexualidades é acompanhada por mudanças subjetivas, sociais e políticas que incidem diretamente na práxis psicanalítica. É importante que o psicanalista, neste contexto, esteja atento, não só recolhendo os efeitos singulares dessas transformações, mas também conhecendo e se posicionando ativamente diante das normas que se esforçam para universalizar os corpos e as formas de existência (Laurent, 2010). Afinal, como "não há clínica do sujeito sem clínica da civilização" (Miller, 2006, p. 21), cabe ao psicanalista apreender como determinada época vive a pulsão através da convivência e da atuação direta no espaço político e social.

Seguindo essa indicação, este ensaio propõe a discussão das experiências trans ${ }^{2}$ com foco nas normativas que definem as possibilidades de retificação do prenome e do sexo nos documentos. Para isso, as regulamentações brasileiras serão examinadas e tensionadas com a Ley de Identidad de Género da Argentina, a partir dos relatos das experiências de três sujeitos. Pretende-se, assim, fomentar reflexões a respeito do lugar do psicanalista diante dessa questão.

\section{O "transexual verdadeiro"}

Sigmund Freud (1905/1996) já indicava que a sexualidade não é algo dado a priori. Ao cunhar a ideia de que a criança é um "perverso polimorfo", o pai da psicanálise evidenciou que há um aspecto pulsional, relativo aos modos de satisfação sexual, que comporta uma infinidade de montagens, definidas, em última instância, contingencialmente. Ou seja, não existe " $\mathrm{A}$ " sexualidade concebida a partir de uma definição universal que englobaria todos os sujeitos. Isso significa considerar que toda lei que se pretenda universal terá sempre um resíduo inassimilável por ela. Assim, como não existe uma fórmula pré-estabelecida que nos autorize traçar um limite rígido entre o normal e o patológico, nem uma definição do que seria moralmente correto ou incorreto, cabe ao sujeito encontrar sua própria solução para se haver com o ponto de "opacidade sexual" (Lacan, 1975-1976/2007).

Nesse processo, não há como desconsiderar a participação dos jogos de poder e das normas socialmente estabelecidas (Foucault, 2001) que tentam disciplinar a pulsão, mesmo sabendo que eles jamais serão suficientes para capturá-la por inteiro. A função do psicanalista, neste caso, seria a de se engajar na articulação entre as normas e as singularidades, buscando alternativas que 
minimizem a segregação e facilitem o laço social. Não se trata de uma tarefa fácil, sobretudo em uma época em que se desvelou a inconsistência do Outro, das grandes narrativas emancipatórias, e em que as normas assumem um caráter imperativo que restringe as possibilidades de ressignificações e respostas dos sujeitos. Nesse sentido, Éric Laurent (2010) é enfático ao recomendar que o psicanalista participe ativamente do debate democrático, opinando sobre questões práticas relacionadas às transformações técnico-científicas dos ideais, de forma a evidenciar que estes não se constituem como a única alternativa. Não se trata de defender os valores tradicionais dos velhos tempos, mas de introduzir intervalos que possam acomodar as invenções de cada um ${ }^{3}$.

Quando nos detemos nas experiências trans, essa questão se torna premente. 0 endocrinologista Harry Benjamin (1966) foi um dos pioneiros a descrever o "fenômeno transexual" no meio médico, propondo um continuum de seis estágios que variavam do "pseudotravestismo" ao "transexualismo verdadeiro". O último se referia aos sujeitos que, por apresentarem um desconforto intermitente com o gênero correspondente ao sexo anatômico designado ao nascimento, teriam a indicação de se submeterem à cirurgia de redesignação sexual como forma de tratamento. Essa concepção sedimentou a narrativa hegemônica que difunde a ideia de que o sujeito transexual é aquele que, desde a tenra infância, demanda viver e ser aceito enquanto uma pessoa do gênero oposto. O quadro vem acompanhado de desconforto persistente com o próprio sexo atribuído, ojeriza pelos órgãos genitais e tendência à depressão e ao suicídio. Sustentada pelos manuais psiquiátricos, pelos profissionais dos serviços assistenciais e por muitos dos sujeitos que endereçam aos serviços médico-jurídicos a demanda de algum tipo de intervenção, essa narrativa engendrou um regime de verdade que caracteriza aquilo que podemos chamar de "dispositivo da transexualidade" (Borba, 2016).

Obviamente, isso não ocorreu sem resistências, lutas e negociações entre os diversos atores sociais. $O$ caso de Waldirene, a primeira mulher a se submeter à cirurgia de redesignação sexual no Brasil, é, nesse sentido, paradigmático. Desde pequena se sentia uma menina, enquanto os irmãos fingiam ser caubóis, ela era a mocinha. "Queria ser igual às minhas irmãs. Por que eu nasci como eu era?" (Rossi, 2018, p. 16). Em dezembro de 1971, após acompanhamento por equipe interdisciplinar, foi diagnosticada como transexual e passou pelo processo cirúrgico para "fixação do seu verdadeiro sexo".

Minha vida antes da operação era um martírio insuportável por ter que carregar uma genitália que nunca me pertenceu. Depois da operação fiquei livre para sempre graças a Deus e ao Dr. Roberto Farina - dos órgãos execráveis que me infernizavam a vida, e senti-me tão aliviada que me pareceu ter criado asas novas para a vida. (Rossi, 2018, p. 8) 
Waldirene tinha tudo para ser considerada uma mulher transexual "de verdade", mas o seu sofrimento não parou por aí. Como na época não existia qualquer regulamentação para esse tipo de procedimento no Brasil, o Ministério Público começou a investigar o cirurgião Roberto Farina por lesão corporal e atentado aos bons costumes. Apesar de o médico se recusar a revelar os dados dos pacientes que ele havia operado, a identidade de Waldirene se tornou pública quando ela entrou na Justiça para a mudança de seus documentos. A mulher foi obrigada a se submeter a exames no Instituto Médico Legal, passando por diversos tipos de constrangimentos. O médico foi ridicularizado e, inicialmente, condenado a dois anos de reclusão. No processo, o promotor do caso, Messias Piva, não mediu suas palavras:

Embora mutilado, Waldir continuará sendo o que sempre foi, ou seja, um homem que mantém relações sexuais com outros homens. Mas a prática de relações sexuais entre pessoas do mesmo sexo será sempre uma aberração, tanto à natureza como à lei. [...] Farina quer que os portadores de distúrbios mentais possam autorizar a realização em seus próprios corpos de cirurgias mutiladoras; que os homossexuais - "bichinhas" - entrem em fila para conseguirem a cirurgia; que os pais de família sejam obrigados a suportar, em seus lares, filhos homossexuais - do que ninguém está livre - e ainda mutilados. (Rossi, 2018, p. 42-43)

No laudo de condenação, o juiz Adalberto Spagnuolo sugeriu que o paciente deveria ter sido submetido a um tratamento psicanalítico de longa duração como tentativa de cura (Rossi, 2018), evidenciando não só um conservadorismo pífio, mas também um profundo desconhecimento em relação à ética sustentada pela psicanálise de orientação lacaniana. Lacan evidenciou que o real pulsional relativo ao sexual é sempre inapreensível por qualquer identidade, lei ou narrativa universal, divergindo-se radicalmente de qualquer ideal de cura. Aliás, uma vez que esse ponto inominável se constitui como uma impossibilidade e, ao mesmo tempo, funciona como baliza e oportunidade de invenção, cabe ao analista acolhê-lo, acompanhando o sujeito na tessitura de seus arranjos singulares - que podem ou não incluir intervenções no corpo -, sem endossar qualquer norma ou ideal de conduta (Macêdo, 2016).

\section{A luta de Neon}

Após diversas lutas na Justiça, apoiadas por pequena parte da sociedade nacional e por boa parte da comunidade científica internacional, a condenação de Roberto Farina foi anulada. Seu legado, no entanto, só foi formalmente reconhecido no meio médico em 1997, quando o Conselho Federal de Medicina autorizou a realização desse tipo de procedimento. Essa medida não veio desacompanhada de uma definição rígida a respeito da transexualidade, assim como de uma padronização da abordagem dos sujeitos assim diagnosticados (Borba, 2016). 
Seguindo a mesma tendência, em 2008, o Sistema Único de Saúde incluiu o "processo transexualizador" em sua cartela de procedimentos, estabelecendo um protocolo norteado pela concepção de que a transexualidade é um transtorno psiquiátrico cujo tratamento é a cirurgia. É notável que, nessa perspectiva, parece não haver outra alternativa de assistência para as pessoas trans que não seja a repetição da narrativa do "transexual verdadeiro" (Borba, 2016) e o enquadramento nos protocolos homogêneos que visam, em última instância, adequar o corpo ao gênero autodesignado. De fato, atualmente, o acompanhamento psicoterápico compulsório, as comprovações de que o sujeito convive bem socialmente com o gênero com o qual se identifica, $a$ ratificação através de laudos médico-psiquiátricos, os tratamentos hormonais, as intervenções cirúrgicas e as lutas na justiça para mudança do prenome e do sexo nos documentos fazem parte da sequência de procedimentos que compõem o percurso de muitos daqueles que se identificam como transexuais (Arán; Murta \& Lionço, 2009). Essa via pré-estabelecida pelo "dispositivo da transexualidade", no entanto, tem sido recusada por alguns a partir do argumento de que ela promove a patologização dos modos de vida que não se adequam às normas (Tenório \& Prado, 2016).

É o caso de uma mulher trans, cuja história foi divulgada por alguns meios de comunicação nacionais (Felitti, 2016). Neon Cunha se sentia uma menina desde pequena e, aos 44 anos de idade, entrou com um processo judicial pedindo a retificação de seus documentos de registro. Ao longo da vida, colocou silicone nos seios e tomou hormônios femininos por um curto período de tempo, interrompendo-os devido ao desconforto que eles Ihe causavam. Ela não tinha nenhum interesse em passar pela cirurgia de transgenitalização ou qualquer outro tipo de controle médico que corroborasse a ideia de que ela era portadora de um quadro psiquiátrico. Em uma entrevista, ela ressaltou que não tinha qualquer incômodo com o seu corpo: "Eu sou uma mulher, tenho um corpo de mulher e esse corpo tem um pênis" (Felitti, 2016, p. 6).

No Brasil, não existe uma legislação que regulamente a retificação do prenome, sexo e imagem nos documentos pessoais. Dessa forma, até pouco tempo, os sujeitos precisavam recorrer à Justiça, ficando à mercê da burocracia, das interpretações e exigências diversas de cada juiz. A solicitação de laudos psiquiátricos e psicológicos era frequente. Algumas vezes, também se exigia um novo laudo produzido por um perito designado pela Justiça com o objetivo de confirmar o diagnóstico. Embora não houvesse qualquer determinação de que o sujeito devesse estar engajado no "processo transexualizador", existia certa tradição no judiciário de conceder parecer favorável especialmente para aqueles que passaram pelo processo cirúrgico (Bento, 2010). Mas o que acontecia com os sujeitos que não aderiam aos protocolos estabelecidos pelos dispositivos médicojurídicos?

É aí que a história de Neon nos surpreende. Em seu processo judicial, ela requisitou não só a retificação de seus documentos, mas também o direito de morte assistida caso o seu pedido não fosse atendido: 
Sou mais uma mulher lutando pelo direito à dignidade que todas nós merecemos e poucas têm acesso. Não há nada mais primário do que a garantia de dignidade, nem mesmo a vida. Não tenho medo da morte. Tenho medo de morrer sem dignidade. A morte assistida seria morrer com os meus queridos ao redor, saber que eu ia ser enterrada com o modelão que eu escolhesse. (Felitti, 2016, p. 14-15)

\section{O "jeitinho brasileiro"}

Diante da ausência de uma lei que garanta direitos básicos às pessoas trans, incluindo a possibilidade de retificação do prenome e do sexo nos documentos, algumas instituições brasileiras começaram a estabelecer regulamentações em torno daquilo que se definiu como "nome social", ou seja, regulamentações locais que reconhecem o nome com o qual a pessoa se identifica. Assistimos, nesse sentido, ao surgimento de algumas resoluções nacionais para que pessoas trans tivessem seus nomes sociais reconhecidos - tais como a Portaria 1.820/2009 (Brasil, 2009), o Decreto 8727/2016 (Brasil, 2016) e a Portaria 33/2018 (Brasil, 2018a), que garantem, respectivamente, o uso do nome social e o reconhecimento da identidade de gênero de travestis e transexuais nos serviços de saúde, na administração pública federal e nas escolas do ensino básico. Tais propostas, no entanto, sempre foram insuficientes para que essas pessoas tivessem acesso, sem passar por algum tipo de violência, a algumas questões básicas que fazem parte do cotidiano de qualquer cidadão - como, por exemplo, abrir uma conta no banco, candidatar-se para uma vaga de emprego, matricular-se em um curso, etc. Ou seja, há, na verdade, a gestão de um profundo paradoxo em relação ao reconhecimento do direito à identidade de gênero que sedimenta uma cidadania pela metade que pouco contribui para melhoria da precariedade existencial das pessoas trans (Bento, 2014).

Esse tipo de segregação se torna especialmente preocupante quando entendemos o lugar de marginalidade e vulnerabilidade que essas pessoas ocupam. Conhecer a realidade e participar das negociações e lutas políticas que fazem parte do cotidiano da população trans é fundamental para que os psicanalistas possam intervir tanto no âmbito singular quanto no âmbito coletivo. Sabese que o Brasil lidera o ranking dos países onde mais se matam pessoas trans. A expectativa de vida desse grupo gira em torno dos 35 anos, taxa menor que a metade da média da população nacional. Poucos conseguem terminar os estudos, não se inserem no mercado formal de trabalho e vivenciam os nefastos reflexos da estigmatização e da ausência de direitos básicos. O acesso à saúde no sistema público também é precário. Esse dado não se refere apenas à escassez de serviços voltados especificamente para aqueles que optam pelo processo de redesignação sexual, mas também às barreiras que esses sujeitos encontram para cuidar de suas demandas mais abrangentes de saúde. Entre as dificuldades, destaca-se o não reconhecimento do nome social por parte dos profissionais dos serviços assistenciais (Núcleo de Direitos Humanos e Cidadania LGBT, 2017). 
Em fevereiro deste ano, foi promulgado um decreto $n^{\circ} 9.278$ sobre a expedição da carteira de identidade (Brasil, 2018b) que garantia que, no documento, fosse incluído o nome com o qual a pessoa se identificava. A nova medida, no entanto, não especificava o local do nome social e tampouco autorizava a supressão do nome do registro civil. Apesar de representar um avanço, na prática não se sabia se isso seria suficiente para reduzir as situações de constrangimento e de exclusão social. Há, nesse sentido, um projeto de lei (PL 5002/2013) - conhecido como Projeto de Lei João Nery, em homenagem ao primeiro homem trans a se submeter à cirurgia de redesignação sexual no Brasil - que tramita pela Câmara dos Deputados desde 2013 com o objetivo de regulamentar a possibilidade de que qualquer pessoa acima de 18 anos tenha o direito de retificar, diretamente nos cartórios, o prenome e o gênero de todos seus documentos sem a necessidade de laudos psiquiátricos ou de autorização judicial.

No dia 01/03/2018, o Supremo Tribunal Federal decidiu que pessoas transexuais e travestis podem alterar a foto, o prenome e o sexo de seus documentos sem burocracias e sem a necessidade de laudos, intervenções médicas ou autorização judicial. Sem dúvida alguma essa decisão representa um avanço na perspectiva dos direitos humanos e da própria democracia (Iotti, 2018). Isso não significa, no entanto, que a questão esteja resolvida. Embora a decisão do Supremo tenha o efeito de lei no Brasil, ela não tem a mesma estabilidade de uma lei inscrita no legislativo. Ademais, para além do registro civil, existem outras demandas das pessoas trans que estão longe de serem contempladas. Manter viva a discussão a respeito do Projeto de Lei João Nery é, nesse sentido, fundamental.

\section{O exemplo da Argentina: à guisa de conclusão}

Na América Latina, a proposta do Projeto de Lei João Nery tem precedentes na Ley de Identidad de Género que foi decretada em 2002 na Argentina, trazendo como novidade a permissão de que cada um defina sua identidade de gênero a partir de sua vivência pessoal. Na época, diversos analistas vinculados à Associação Mundial de Psicanálise se posicionaram. Uma questão recorrente nessas discussões se refere à possibilidade de que essa lei corrobore a tendência contemporânea de se prescindir da marca do Outro, provocando, consequentemente, a segregação típica das comunidades de gozo que marcam a atualidade. Por outro lado, há quem entenda que, nesse mesmo ato de autoenunciação, há um apelo de reconhecimento do Outro que renova a consistência de um outro tipo de alteridade, possibilitando, ao mesmo tempo, uma melhora na qualidade de vida e a inclusão social dos sujeitos (Schnitzer, 2013). Não se trata, neste caso, de apostar na inserção das diferenças no coletivo - afinal, isso poderia contribuir para a constituição de comunidades de gozo identitárias em torno de uma mesma maneira de gozar -, mas na desinserção estrutural do gozo como forma de fazer caber a singularidade de cada um no espaço social (Miller, 2009).

De fato, a prática clínica nos mostra que a retificação dos documentos pode constituir, por si só, como uma solução para alguns. Para alguns, não para todos. É o caso da ativista Marlene 
Wayar (2013), radicada na Argentina, que, apesar de se identificar com seu nome social - uma mistura de Marlene Dietrich com o sobrenome do pai -, optou por não fazer mudanças em seu corpo nem retificar os seus documentos. A mulher faz questão de se autodesignar como travesti, ressaltando que se trata de uma questão política: "[...] é uma posição política não fazer a mudança para não me invisibilizar atrás de uma mulher, porque eu sou travesti" (Wayar, 2013, p. 75). Eis a sua posição singular: ela prefere continuar sendo travesti - e não mulher -, questionando, assim, as normas binárias que determinam os modos de expressão das sexualidades e dos gêneros.

Ora, sabemos que toda lei produz um resíduo irredutível e que nunca será suficiente para contemplar os sujeitos e suas singularidades. Neon e Marlene revelam que é justamente neste ponto em que reside a potência política de cada um. Ambas querem ser chamadas pelos seus nomes e, para isso, surpreendem a todos e impulsionam reflexões e transformações nos dispositivos sociais.

Devemos reconhecer, no entanto, que, ainda que toda lei seja uma ficção fundada a partir de um ato violento (Teixeira, 2015) que segrega e exclui muitas formas de existência, existem algumas que abrem um leque maior de possibilidades para que cada um construa sua própria resposta diante do real do sexo. Não se trata de acreditar que há um ideal possível para todos, mas de apostar em ficções que produzam fendas menos estreitas de onde o sujeito possa emergir sem colocar tanto em risco sua própria vida. Neon pede a morte assistida. Marlene se recusa a retificar seus documentos. Diante disso, não há como um analista, comprometido com a subjetividade de sua época, se furtar a um posicionamento.

\section{Notas:}

${ }^{1}$ Trecho do poema de Cecília Meireles citado pela atual presidente do Supremo Tribunal Federal (STF), Cármen Lúcia, ao sustentar o seu voto favorável para que as pessoas trans possam alterar prenome e sexo no registro civil sem a necessidade de intervenções médicas e processos judiciais.

2 Neste ensaio, o termo trans é utilizado na tentativa de fazer um contraponto ao que o discurso médico-psiquiátrico denominou como "transexualismo" ou, mais recentemente, como "disforia de gênero", referindo-se a uma infinidade de modos de vida que rompe com a suposta correspondência entre sexo biológico, identidade de gênero e orientação sexual, incluindo as diversas formas de transexualidades e travestilidades.

${ }^{3}$ Foi o que aconteceu, por exemplo, quando Jacques-Alain Miller (2013) fez uma intervenção no Senado Francês na ocasião da discussão do projeto de lei que propunha a legalização do casamento entre pessoas do mesmo sexo. Ao que tudo indica, o psicanalista, estrategicamente, deixou para falar sobre a questão dos filhos no final, ressaltando que o ponto central não diz respeito a orientação sexual dos pais, mas ao desejo particularizado em relação à criança. Abre-se, assim, um intervalo que possibilita um melhor acolhimento dos arranjos singulares, evidenciando, ao mesmo tempo, a tendência da orientação lacaniana de valorizar a atualidade clínica de propostas de laços alternativos ao Édipo clássico. 


\section{Referências Bibliográficas}

Arán, M., Murta, D. \& Lionço, T. (2009, jul.-ago.). Transexualidade e saúde pública no Brasil. Ciência e Saúde Coletiva, 14(4), 1141-1149. doi: 10.1590/S1413-81232009000400020.

Bento, B. (2004). Nome social para pessoas trans: cidadania precária e gambiarra legal. Contemporânea, 4(1), 165-182.

Bento, B. (2010). Identidade legal de gênero: reconhecimento ou autorização? In Costa, H.; Bento, B.; Garcia, W.; Inácio, E. \& Peres, W. S. (Orgs.). Retratos do Brasil homossexual: fronteiras, subjetividades e desejos (pp. 71-82). São Paulo: Ed. USP - imprensa oficial.

Benjamin, H. (1966). The transsexual phenomenon. New York: The Julian Press.

Borba, R. (2016). O Des-Aprendizado de si: transexualidades, interação e cuidado em saúde. Rio de Janeiro: FioCruz.

Brasil. Ministério da Saúde. (2009, 14 ago.). Portaria no 1.820 de 13 de agosto de 2009. Dispõe sobre os direitos e deveres dos usuários da saúde. Diário Oficial da União, 80.

Brasil. (2016, 29 abr.). Decreto no 8.727 de 28 de abril de 2016. Dispõe sobre o uso do nome social e o reconhecimento da identidade de gênero de pessoas travestis e transexuais no âmbito da administração pública federal direta, autárquica e fundacional. Diário Oficial da União, 1.

Brasil. Ministério da Educação. (2018a, 18 jan.). Portaria n 33 de 17 de janeiro de 2018. Diário Oficial da União, 10.

Brasil. (2018b, 6 fev.). Decreto no 9.278 de 5 de fevereiro de 2018. Regulamenta a Lei no 7.116, de 29 de agosto de 1983, que assegura validade nacional às Carteiras de Identidade e regula sua expedição. Diário Oficial da União, 3.

Foucault, M. (2001). História da sexualidade 1: a vontade de saber. Rio de Janeiro: Editora Graal.

Freud, S. (1996). Três ensaios sobre a teoria da Sexualidade. In J. Salomão (Trad.) Edição standard brasileira das obras psicológicas completas de Sigmund Freud (Vol. 7, pp. 128-229). Rio de Janeiro: Imago (Trabalho original publicado em 1905).

Iotti, P. (2018, mar.). STF e TSE fazem História ao afirmar a Cidadania de Transexuais e Travestis. Justificando. Recuperado de http://justificando.cartacapital.com.br/2018/03/02/stf-e-tsefazem-historia-ao-afirmar-cidadania-de-transexuais-e-travestis.

Lacan, J. (2007). O Seminário, livro 23: o sinthoma. Rio de Janeiro: Jorge Zahar (Trabalho original publicado em 1975-1976).

Laurent, É. (2010, dez.). O analista cidadão. Curinga - Revista da Escola Brasileira de Psicanálise, (31), 7-13.

Macêdo, L. F. de. (2016). Escolhas do sexo; da norma a invenção. In Val, A. C.; Gomes, G. de. L.; Dias, F. M. V. Multiplicando os gêneros nas práticas em saúde (pp. 173-191). Ouro Preto: Editora UFOP. 
Miller, J.-A. (2006). Você quer mesmo ser avaliado: entrevistas sobre uma máquina de impostura. São Paulo: Manole.

Miller, J.-A. (2013). Intervención en el Senado francés. In Torres, M.; Schnitzer, G.; Antuña, A. \& Peidro, S. (Compiladores). Transformaciones: ley, diversidade, sexuación (pp. 129-144). Buenos Aires: Grama Ediciones.

Rossi, P. (2018, mar.). "Monstro, prostituta, bichinha": como a Justiça condenou a $1^{\text {a }}$ cirurgia de mudança de sexo do Brasil e sentenciou médico à prisão. $B B C$ Brasil. Recuperado de http://www.bbc.com/portuguese/geral-43561187.

Schnitzer, G. (2013). Nuestra pasión por lo nuevo. In Torres, M.; Schnitzer, G.; Antuña, A. \& Peidro, S. (Compiladores). Transformaciones: ley, diversidade, sexuación (pp.167-174). Buenos Aires: Grama Ediciones.

Tenório, L. F. P. \& Prado, M. A. M. (2016). Os impactos e contradições da patologização das transidentidades e argumentos para a mudança de paradigma. In Val, A. C.; Gomes, G. de. L.; Dias, F. M. V. Multiplicando os gêneros nas práticas em saúde (pp.130-144). Ouro Preto: Editora UFOP.

Teixeira, A. (2017, nov.). A fundação violenta do universal. Derivas Analíticas, (3). Recuperado de http://revistaderivasanaliticas.com.br/index.php/universal.

Felitti, C. (2016, jul.). Transexual pede morte assistida se não puder mudar nome e gênero. Folha de São Paulo on line. Recuperado de http://www1.folha.uol.com.br/cotidiano/2016/07/1797087-transexual-pede-morte-assistidase-nao-puder-mudar-nome-e-genero.shtml.

Wayar, M. (2013). "No quiero invisibilizarme detrás de una mujer". In Torres, M.; Schnitzer, G.; Antuña, A. \& Peidro, S. (Compiladores). Transformaciones: ley, diversidade, sexuación (pp. 6983). Buenos Aires: Grama Ediciones.

Citacão/Citation: Val, A. C. (nov. 2017 a abr. 2018). Me chame pelo meu nome. Revista aSEPHallus de Orientação Lacaniana, 13(25), 6-16. Disponível em www.isepol.com/asephallus. doi: 10.17852/1809709x.2019v12n25p6-16

Editor do artigo: Tania Coelho dos Santos.

Recebido/Received: 10/12/2016 / 12/10/2016.

Aceito/Accepted: 20/06/2017 / 06/20/2017.

Copyright: ( 2018 Associação Núcleo Sephora de Pesquisa sobre o moderno e o contemporâneo. Este é um artigo de livre acesso, que permite uso irrestrito, distribuição e reprodução em qualquer meio, desde que o autor e a fonte sejam citados/This is an open-access article, which permites unrestricted use, distribution, and reproduction in any medium, provided the author and source are credited. 